\title{
Radiographic evaluation of bioactive glass-ceramic grafts in postero-lateral lumbar fusion
}

\author{
K Ido*, ${ }^{*}$, Y Asada ${ }^{1}$, T Sakamoto ${ }^{1}, \mathrm{R} \mathrm{Hayashi}^{1}$ and S Kuriyama ${ }^{1}$ \\ ${ }^{1}$ Department of Orthopaedic Surgery, Japanese Red Cross Society, Wakayama Medical Center, Wakayama, Japan
}

\begin{abstract}
Study design: Follow-up study of bioactive glass-ceramic graft for postero-lateral fusion (PLF) in the lumbar spine was performed using plain radiography.

Objectives: To investigate the fusion state of the porous stick type of bioactive glass-ceramic which has been used in PLF in the lumbar spine, by plain radiography, and to evaluate the usefulness of this technique.

Methods: Fourteen patients who underwent PLF using apatite and wollastonite-containing glass-ceramic (A-W $\cdot \mathrm{GC})$ were followed-up for more than 1 year and 6 months by plain radiography.

Results: Six patients who were followed up for more than 2 years were considered to have obtained subtotal or total fusion.

Conclusion: PLF using A-W - GC mixed with autologous grafted bone can preserve bone stock without the need to harvest a bone graft from the iliac crest and will be useful for PLF in the lumbar spine.
\end{abstract}

Spinal Cord (2000) 38, 315-318

Keywords: postero-lateral fusion; lumbar spine; bioactive glass-ceramic; osteoconduction; plain radiography

\section{Introduction}

Postero-lateral fusion (PLF) in the lumbar spine is a commonly performed procedure mainly for degenerative disorders of the lumbar spine. ${ }^{1,2}$ The use of PLF surgery has been increasing in parallel with the development of spinal instrumentation surgery. ${ }^{3-6}$ Traditionally, PLF has included various types of bone grafts. ${ }^{7-13}$ Although an autologous bone graft seems to be an excellent way of obtaining a successful fusion, it also has several disadvantages, the main one being the need to harvest a bone graft from the iliac crest. Furthermore, in cases of long fusion, bone grafts from the bilateral iliac crest may be required in order to obtain solid fusion. Recently, we have used porous sticks of apatite and wollastonite-containing glassceramic (A-W - GC) mixed with autologous bone. A$\mathrm{W} \cdot \mathrm{GC}$ is one of the bioactive glass-ceramics that was developed at Kyoto University in 1982 and has been applied for many clinical cases. ${ }^{14}$ A porous stick of AW . GC with a porosity of $70 \%$ has an osteoconductive capacity and is also less toxic to the human body. However, it has several advantages in that it accelerates bone ingrowth, undergoes a change to bone and disappears, and also reduces the volume of bone that has to be harvested from the iliac crest. Although

*Correspondence: K Ido, Department of Orthopaedic Surgery, Kurashiki Central Hospital, 1-1, 1-chome, Miwa, Kurashiki-city, Okayama, 710-8602, Japan radiographic evaluation of lumbar spine fusion is not easy, ${ }^{15,16}$ a porous stick of A-W - GC can be observed by plain radiography from the early postoperative period to the final stage when solid fusion has been achieved.

The purpose of this study was to investigate the fusion state of the porous stick type of A-W - GC which has been used in PLF by plain radiography, and to evaluate the usefulness of this technique.

\section{Materials and methods}

During a 2-year period between 1996 and 1997, 14 patients underwent PLF using the porous stick type of A-W - GC. Eleven of these patients who were followed for more than 1 year and 6 months by plain radiography were included in this study. The clinical data are summarized in Table 1. The patients comprised eight women and three men, with an average age of 58 years. Single-level fusion was performed on five patients, and multi-level fusion was performed on six.

In the five patients who underwent single-level fusion, posterior lumbar interbody fusion (PLIF) using the Varlock system was performed with the support of posterior spinal instrumentation such as Steffee VSP and PLF using porous sticks of A-W - GC mixed with autologous grafted bone. 
Table 1 The clinical data

\begin{tabular}{|c|c|c|c|c|c|c|}
\hline Case & Age & Sex & Disease & Fusion level & Instruments & Follow-up \\
\hline 1 & 73 & $\mathrm{~F}$ & Degenerative spondylolisthesis (L4) & $\mathrm{L} 4 / 5$ & Varlock, ASD & $2 \mathrm{Y}$ \\
\hline 2 & 60 & $\mathrm{~F}$ & Spondylolytic spondylolisthesis (L4) & $\mathrm{L} 4 / 5$ & Varlock, ASD & $3 \mathrm{Y}$ \\
\hline 3 & 24 & M & Compression fracture (L3, L4) & $\mathrm{L} 3-5$ & TSRH & $1 \mathrm{Y} 6 \mathrm{M}$ \\
\hline 4 & 59 & $\mathrm{~F}$ & Degenerative spondylolisthesis (L4) & $\mathrm{L} 4 / 5$ & Varlock, Steffee VSP & $3 \mathrm{Y}$ \\
\hline 5 & 50 & M & Burst fracture (L4) & $\mathrm{L} 3-5$ & TSRH & $2 \mathrm{Y} 6 \mathrm{M}$ \\
\hline 6 & 65 & $\mathrm{~F}$ & Degenerative spondylolisthesis (L4) & $\mathrm{L} 4 / 5$ & Varlock, Steffee VSP & $1 \mathrm{Y} 6 \mathrm{M}$ \\
\hline 7 & 52 & M & Compression fracture (L4) & L3-S & TSRH & $2 \mathrm{Y} 6 \mathrm{M}$ \\
\hline 8 & 61 & $\mathrm{~F}$ & Degenerative spondylolisthesis (L4) & $\mathrm{L} 4 / 5$ & Varlock, Steffee VSP & $2 \mathrm{Y}$ \\
\hline 9 & 58 & $\mathrm{~F}$ & Degenerative spondylolisthesis (L4) & $\mathrm{L} 3-5$ & Varlock, TSRH & $1 \mathrm{Y} 6 \mathrm{M}$ \\
\hline 10 & 68 & $\mathrm{~F}$ & Degenerative spondylolisthesis & $\mathrm{L} 2-5$ & Moss Miami & $1 \mathrm{Y} 6 \mathrm{M}$ \\
\hline 11 & 68 & $\mathrm{~F}$ & Degenerative spondylolisthesis & $\mathrm{L} 3-5$ & TSRH & $1 \mathrm{Y} 6 \mathrm{M}$ \\
\hline
\end{tabular}

Table 2 The criteria for the evaluation of fusion state of grafted porous A-W - GC by plain radiography

\begin{tabular}{|c|c|}
\hline Stage A: & $\begin{array}{l}\text { There was no change of grafted porous sticks of } \\
\text { A-W } \text {. GC }\end{array}$ \\
\hline Stage B: & $\begin{array}{l}\text { A slight change was observed only in a little part } \\
\text { of grafted porous sticks of A-W . GC }\end{array}$ \\
\hline Stage C: & $\begin{array}{l}\text { A change in configuration and/or density of } \\
\text { grafted porous sticks of A-W . GC was } \\
\text { observed in less than one-third of them }\end{array}$ \\
\hline Stage D: & $\begin{array}{l}\text { A change in configuration and/or density of } \\
\text { grafted porous sticks of A-W . GC was } \\
\text { observed between one-third and two-thirds of } \\
\text { them (moderate fusion state) }\end{array}$ \\
\hline Stage E: & $\begin{array}{l}\text { A change in configuration and/or density of } \\
\text { grafted porous sticks of A-W . GC was } \\
\text { observed in more than two-thirds of them } \\
\text { (subtotal fusion state) }\end{array}$ \\
\hline Stage F: & $\begin{array}{l}\text { Total change of grafted porous sticks of A-W } \\
\text { GC was observed and grafted porous A-W } \\
\text { GC itself disappeared completely (total fusion } \\
\text { state) }\end{array}$ \\
\hline
\end{tabular}

Among the six patients who underwent multi-level fusion, posterior instrumentation surgery was performed using the TSRH system and Moss Miami system on four and two patients, respectively. Porous sticks of A-W - GC mixed with autologous bone were applied in the same manner as that for PLF in these six patients. Each patient was allowed to walk with the support of a hard corset within 2 weeks, and no differences in postoperative rehabilitation were detected between the two groups.

Postoperative antero-posterior plain radiography was performed once a month to evaluate bone fusion and changes in the grafted porous A-W - GC. Our original criteria for checking the changes in the grafted porous A-W . GC by plain radiography were used for evaluation of the fusion state (Table 2).

\section{Results}

The data for radiographic evaluation are shown in Table 3. All of the six patients followed up for more
Table 3 The data for radiographic evaluation

\begin{tabular}{lccccccc}
\hline Case & $3 M$ & $6 M$ & $1 Y$ & $1 Y 6 M$ & $2 Y$ & $2 Y 6 M$ & $3 Y$ \\
\hline 1 & $\mathrm{C}$ & $\mathrm{D}$ & $\mathrm{E}$ & $\mathrm{F}$ & $\mathrm{F}$ & - & - \\
2 & $\mathrm{~B}$ & $\mathrm{C}$ & $\mathrm{D}$ & $\mathrm{E}$ & $\mathrm{E}$ & $\mathrm{F}$ & $\mathrm{F}$ \\
3 & $\mathrm{~B}$ & $\mathrm{C}$ & $\mathrm{D}$ & $\mathrm{E}$ & - & - & - \\
4 & $\mathrm{~B}$ & $\mathrm{C}$ & $\mathrm{D}$ & $\mathrm{E}$ & $\mathrm{F}$ & $\mathrm{F}$ & $\mathrm{F}$ \\
5 & $\mathrm{~B}$ & $\mathrm{C}$ & $\mathrm{D}$ & $\mathrm{E}$ & $\mathrm{F}$ & $\mathrm{F}$ & - \\
6 & $\mathrm{~B}$ & $\mathrm{~B}$ & $\mathrm{C}$ & $\mathrm{E}$ & - & - & - \\
7 & $\mathrm{~A}$ & $\mathrm{~B}$ & $\mathrm{C}$ & $\mathrm{D}$ & $\mathrm{E}$ & $\mathrm{E}$ & - \\
8 & $\mathrm{~B}$ & $\mathrm{C}$ & $\mathrm{D}$ & $\mathrm{D}$ & $\mathrm{E}$ & - & - \\
9 & $\mathrm{~B}$ & $\mathrm{C}$ & $\mathrm{E}$ & $\mathrm{F}$ & - & - & - \\
10 & $\mathrm{~B}$ & $\mathrm{~B}$ & $\mathrm{C}$ & $\mathrm{D}$ & - & - & - \\
11 & $\mathrm{~A}$ & $\mathrm{~B}$ & $\mathrm{C}$ & $\mathrm{D}$ & - & - & - \\
\hline
\end{tabular}

than 2 years were classified into stage $\mathrm{E}$ or $\mathrm{F}$, which represented subtotal or total fusion. The other five patients followed up for between 1 year and 6 months were classified into stage $\mathrm{D}, \mathrm{E}$ or $\mathrm{F}$, accounting for two, two and one patients respectively. Two patients at stage D who were followed up for 1 year and 6 months showed moderate ongoing fusion. No differences were observed in age, sex, type of instrumentation and extent of PLF.

Case 1

A 73-year-old woman with L4 degenerative spondylolisthesis underwent PLIF and PLF using the Varlock system and the ASD system. Plain radiography at 6 months, 1 year, 1 year and 6 months, and 2 years demonstrated stage $\mathrm{D}, \mathrm{E}, \mathrm{F}$, and $\mathrm{F}$, respectively (Figure 1a,b).

Case 5

A 50-year-old man with L4 burst fracture underwent PLF between L 3 and L5 using the TSRH system. Plain radiography at 6 months, 1 year, 2 years, and 2 years and 6 months demonstrated stage $\mathrm{C}, \mathrm{D}, \mathrm{F}$, and F, respectively (Figure 2a,b). 


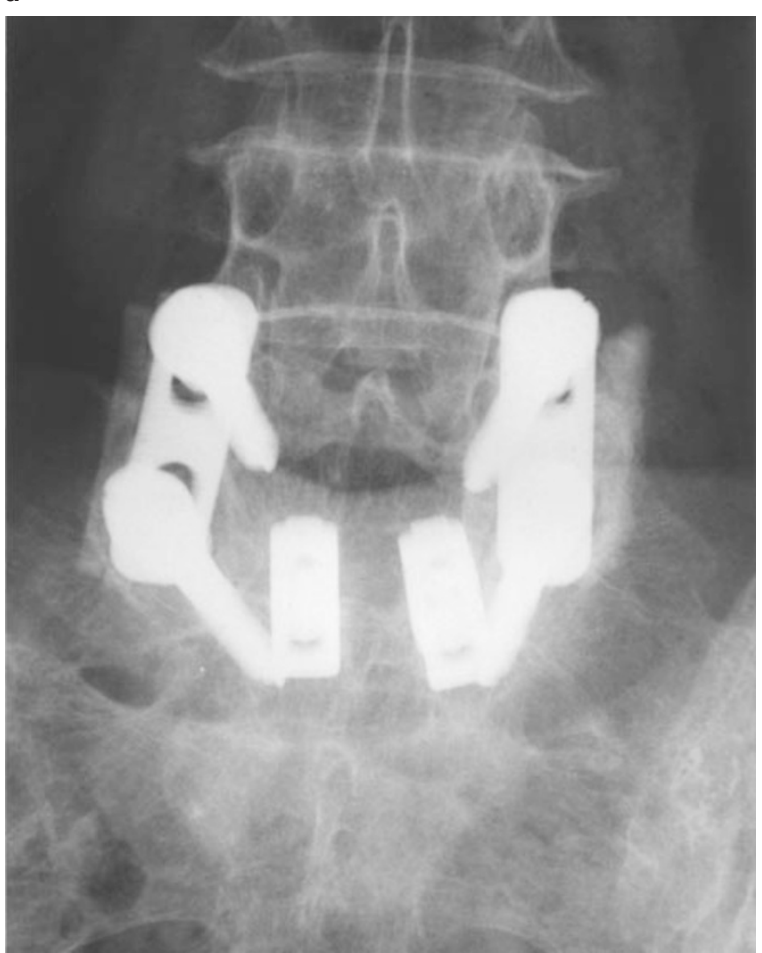

b

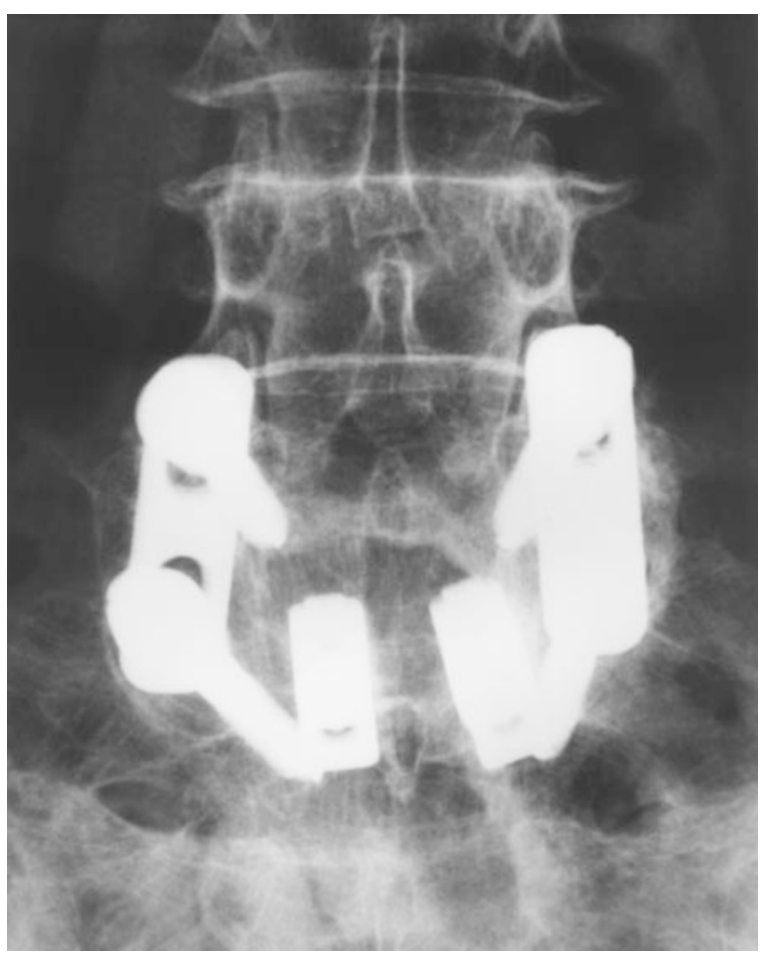

Figure 1 A 73-year-old woman with L4 degenerative spondylolisthesis. (a) Anteroposterior plain radiograph at 6 months after the operation demonstrated stage D. (b) Anteroposterior plain radiograph at 2 years after the operation demonstrated stage $\mathrm{F}$

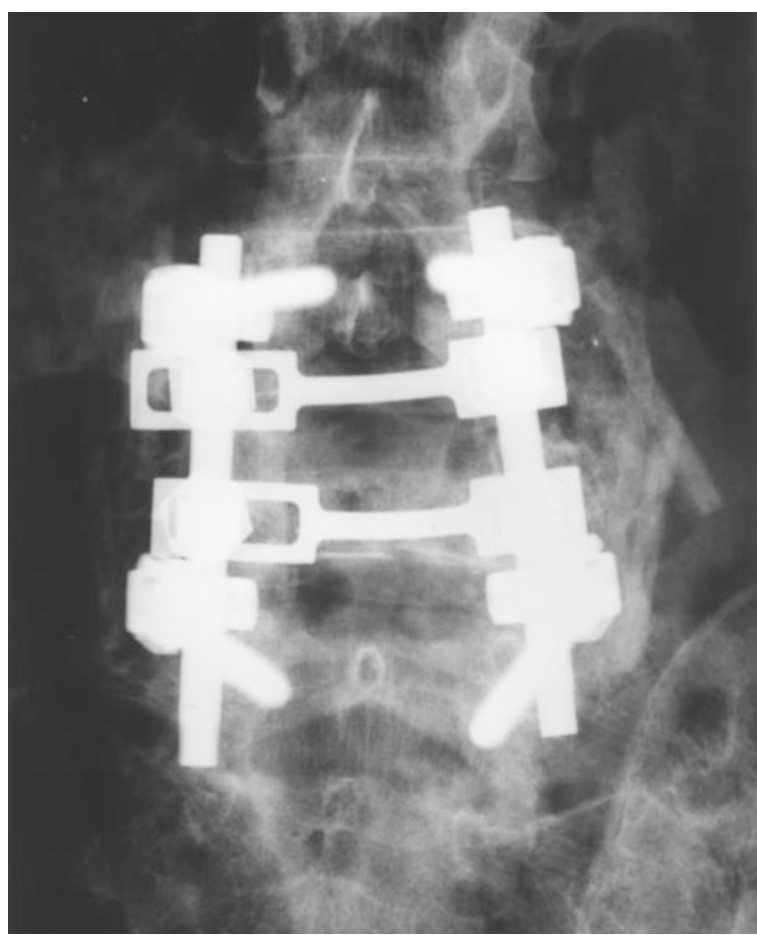

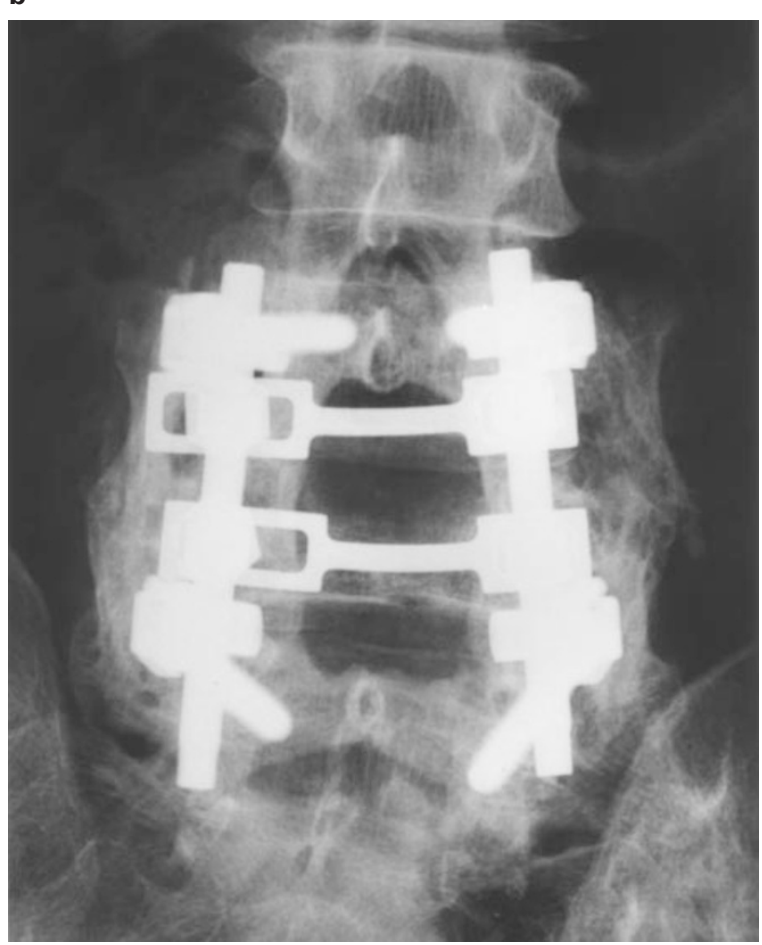

Figure 2 A 50-year-old man with L4 burst fracture. (a) Anteroposterior plain radiograph at 1 year after the operation demonstrated stage D. (b) Anteroposterior plain radiograph at 2 years and 6 months after the operation demonstrated stage F 


\section{Discussion}

PLF in the lumbar spine has included various types of bone grafts and/or additional osteoconductive biomaterials. $^{7-13}$ As allografting is seldom done in Japan, the use of osteoconductive biomaterials has developed to reduce the disadvantages of bone grafting from the iliac crest, especially in patients undergoing multi-level PLF. Furthermore, PLF has been necessary even in PLIF using the Varlock system, which seems unable to unite with the endplate of the vertebral body. Thus, PLF using osteoconductive biomaterials mixed with grafted bone has been considered useful for patients undergoing surgery of the lumbar spine, and has been performed in PLIF and PLF surgery.

A-W - GC, which has osteoconductive capacity and is less toxic, has been used for various clinical applications, such as artificial bone augmentation, as an intervertebral spacer, or artificial vertebral body, and also in cementless total hip prostheses. Recently, we attempted to use porous $\mathrm{A}-\mathrm{W} \cdot \mathrm{GC}$ as a femoral cement plug in total hip arthroplasty. The porous A$\mathrm{W} \cdot \mathrm{GC}$ cement plug was found to change completely to cancellous bone at 2 years of follow-up, and the A$\mathrm{W} \cdot \mathrm{GC}$ itself disappeared completely. The radiographic data for our patients in whom the porous stick type of A-W - GC was used were considered to be very similar to these findings. In fact, the porous stick type of A-W . GC in PLF had a tendency to change to a bone-like structure nearly 2 years after the operation, while moderate or subtotal fusion was obtained at 1 year and 6 months.

PLIF and PLF using spinal instruments have developed remarkably during the last decade. These procedures have several advantages for obtaining spinal stability, solid spinal fusion and relief of pain. However, they also have some disadvantages, including the need to harvest a bone graft from the iliac crest. The use of osteoconductive biomaterials such as the porous stick type A-W - GC will make it possible to preserve stocked bone for future use.

In conclusion, radiographic evaluation of the porous stick type of A-W - GC grafted in the lumber spine demonstrated satisfactory bone fusion at around 2 years after implantation. This porous stick of AW . GC appears to be a promising substitute for PLF in the lumbar spine.

\section{References}

1 Axelsson $\mathrm{P}$ et al. Posterolateral lumbar fusion. Acta Orthop Scand 1994; 65: 309-314.

2 Fraser RD. Interbody, posterior, and combined lumbar fusions. Spine 1995; 20: $167 \mathrm{~S}-177 \mathrm{~S}$.

3 Tejano NA, Puno R, Ignacio JMF. The use of implantable direct current stimulation in multilevel spinal fusion without instrumentation. A prospective clinical and radiographic evaluation with long-term follow-up. Spine 1996; 21: 1904-1908.

4 Fischgrund JS et al. Degenerative lumbar spondylolisthesis with spinal stenosis: A prospective, randomized study comparing decompressive laminectomy and arthrodesis with and without spinal instrumentation. Spine 1997; 22: $2807-2812$.

5 Thomsen $\mathrm{K}$ et al. The effect of pedicle screw instrumentation on functional outcome and fusion rates in posterolateral lumbar spinal fusion: A prospective, randomized clinical study. Spine 1997; 22: $2813-2822$.

6 Christensen FB et al. Functional outcome after posterolateral spinal fusion using pedicle screws: comparison between primary and salvage procedure. Eur Spine J 1998; 7: 321 - 327.

7 An HS, Lynch K, Toth J. Prospective comparison of autograft vs. allograft for adult posterolateral lumbar spine fusion: differences among freeze-dried, frozen, and mixed grafts. $J$ Spinal Disord 1995; 8: $131-135$.

8 Butterman GR, Glazer PA, Bradford DS. The use of bone allografts in the spine. Acta Orthop Rel Res 1996; 324: 75-85.

9 Sheehan JP et al. Molecular methods of enhancing lumbar spine fusion. Neurosurgery 1996; 39: $548-554$.

10 Boden SD et al. The use of an osteoinductive growth factor for lumbar spinal fusion. Part I: biology of spinal fusion. Spine 1995; 20: $2626-2632$.

11 Boden SD et al. The use of an osteoinductive growth factor for lumbar spinal fusion. Part II: study of dose, carrier, and species. Spine 1995; 20: 2633 - 2644.

12 Boden SD et al. In vivo evaluation of a resorbable osteoinductive composite as a graft substitute for lumbar spinal fusion. J Spinal Disord 1997; 10: $1-11$.

13 Delécrin $\mathbf{J}$ et al. Influence of local environment on incorporation of ceramic for lumbar fusion. Comparison of laminar and intertransverse sites in a canine model. Spine 1997; 22: $1683-$ 1689

14 Kokubo T et al. Mechanical properties of a new type of apatitecontaining glass-ceramic for prosthetic application. J Mat Sci 1985; 20: $2001-2004$.

15 Kant AP et al. Evaluation of lumbar spine fusion. Plain radiographs versus direct exploration and observation. Spine 1995; 20: $2313-2317$.

16 Blumenthal SL, Gill K. Can lumbar spine radiographs accurately determine fusion in postoperative patients? Spine 1993; 18: $1186-1189$. 